\title{
Improve Adult Health Life in Western Sydeny Through Health Promotion Models
}

\author{
Hamzeh Khudeir \\ Master of Research Health Management Western Sydney of University \\ DUA'A Khudeir
}

doi: 10.19044/esj.2017.v13n15p376 URL:http://dx.doi.org/10.19044/esj.2017.v13n15p376

\begin{abstract}
This report will focus on a new health development initiative for the Western Sydney Adolescents and their health needs in terms of promoting physical activity and exercise because it helps them live longer and better lives and become more energetic. The target group are fairly sedentary individuals and consume copious amounts of energy dense foods, which are contributing to the burgeoning obesity risk factors in the community. A sedentary lifestyle contributes towards a range of cardiovascular diseases and health problems including heart disease, obesity, high blood pressure, high cholesterol and many types of cancers (Meyer, 2007). Successfully tackling obesity in a health promotion context, is a long-term, large-scale commitment that will require both individual responsibility and action together with a population-based approach, driven by partnerships between governments, businesses, and communities. The current prevalence of obesity in the population has been at least 30 years in the making, and will take considerable time to reverse the trends and its impacts and determinants on health (Roth, 2011). This article will outline the costing requirements and the evaluation methods that will be used in our adolescent obesity health promotion and prevention management strategy. This will be achieved by using a combination of educational and awareness campaigns, public advertising, healthy urban planning, imposing a ban on canteen junk food and establishing a health and wellbeing telephone hotline and social networking group. This will be evaluated for feasibility using cost-benefit analysis to determine whether each strategy or approach is to be implemented or not.
\end{abstract}

Keywords: Health, Western Sydney. 


\section{Introduction}

Western Sydney is one of the most multi-cultural areas of Sydney with over 180,000 residents populating the area from over 60 different nationalities and contains over 2 million residents total.

The rate of obesity has more than doubled over the past 20 years in the US, but has almost tripled in Australia in the same timeframe (ABS, 2009). Obesity was estimated to cost Australia AU\$58 billion in 2008, a tripling in costs since 2005. The World Health Organisation (WHO) defines overweight and obesity as "abnormal or excessive fat accumulation that may impair health". WHO defines 'overweight' as a Body Mass Index (BMI) equal to or more than 25, and 'obesity' as a BMI equal to or more than 30 . There is evidence that chronic diseases in populations increases progressively from a BMI of 21 or greater (Krebs 2007)

According to (Roth, 2009) $86 \%$ of Australian teenagers are not getting the recommended amount of daily exercise and $80 \%$ are not consuming the recommended daily intake of fruit and vegetables. Combined with increasing sedentary lifestyles and high consumption of high calorie junk food, the obesity rates have been continuously increasing over the past 30 years in Australia (Roth, 2009).

Appendix 12, clearly illustrates the fascinating trend of increasing overweight and obesity amongst children that has steadily increased over the past 20 years. Among boys aged 7-15 years, overweight and obesity increased from $11 \%$ in 1985 to $20 \%$ in 1995 , rising to almost $24 \%$ in 2007. In girls the prevalence increased from $12 \%$ in 1985 to $21.5 \%$ in 1995 , and rising to $25.8 \%$ in 2007 (Roberts 2009).

Obesity and associated illness creates a substantial financial burden to the community. The cost of treatment of obesity within the health care system was estimated to be $\$ 393$ million (Cancer Council Australia, 2010). In South Western Sydney, physical inactivity has been estimated to cost at least $\$ 596$ million each year in direct health care costs that could be better utilised in addressing other healthcare needs. Current estimates suggest that savings of up to $\$ 8$ million each year could be possible for every $1 \%$ increase in the proportion of the population that is sufficiently active (Health Victoria, 2006). According to SWAHS(2006) for every one percentage point rise in BMI, future direct national healthcare expenditures will increase by $2.3 \%$ so there are significant cost savings and benefits of enacting an obesity prevention plan as soon as possible.

Some of the causes of Adolescent Obesity are the following:

- Increasing energy intake

- Increasingly sedentary lifestyles 
- Decreased walking, cycling, and transport-related physical activity

- Changes in family structures and parents work patterns

- Socio-economic factors

- Role and influence of the media in childhood obesity.

(Health Victoria ,2006)

\section{Risk Factors}

Teenagers who have a Body Mass Index over 30 are considered medically obese and are at greater risk of developing serious health problems, especially later in life. These diseases are: diabetes, biliary calculus, respiratory insufficiency, nocturnal apnoea, cardiovascular diseases, arterial hypertension, arthritis of backbone and of lower limbs, fertility anomalies, cancer (Cancer Council, 2009).

According to the Australian Bureau of Statistics, National Health Survey (2009), the percentage of overweight or obese people was over $60 \%$ for both men and women. The biggest age category is men and women aged between 55-64 years of age who are 35\% overweight and 30\% obese respectively. Furthermore, $13 \%$ of 18-24 year olds are obese and $15 \%$ of 25 34 year olds are also obese. This is a highly concerning statistic news that these young individuals are already obese at a young age and are facing a real risk of dying prematurely. As we can see from the table in appendix 3, Bankstown rates as the $3^{\text {rd }}$ most obese suburb in Sydney, with a staggering $51 \%$ of the population being either overweight or obese. This represents a health epidemic in which action must be taken to reduce these numbers. Therefore, by examining the data we can see a strong correlation between socio-economic status and obesity problems (ABS, 2009).

According to Appendix 6, Heilman(2006) tabulates the rise of worldwide daily calorie intake since 1965 and its correlation with increasing obesity rates, especially in the West (Heilman, 2006). The most significant conclusion is that calorie intake has increased by 5000 kilojoules per day over a 40 year time span. Due to excessive calorie consumption being a strong cause of obesity we can see this as one of the main causes and will be accounted for in the prevention strategy, which will be discussed in the following sections of this paper.

From appendix 7, we can also see the global distribution of daily calorie intake, with a trend amongst virtually all Western nations having the highest levels consumption. Comparing this to the developing countries which have relatively lower levels because of the scarcity and inferior quality of food (Profil, 2009). 


\section{International Charters}

The Bangkok charter focuses on the health inequality between developed and the developing world, impact of urbanisation, changing trends of communication and consumption in a globalised world, environmental change and commercialisation.

In terms of adolescent obesity they are focused on the following priority areas:

- Building alliances and partnerships with private, public, nongovernmental organizations to create sustainable obesity control.

- Investing in sustainable policies, actions and infrastructure to address the determinants and causes of obesity.

- Building capacity for policy development, health promotion practice and literacy to reduce obesity.

- Regulate and legislate against obesity.

- Health Advocacy for adolescent obesity.

(WHO, 2012)

The Ottawa Charter focuses on five action areas for health promotion, in terms of adolescent obesity management, including the following:

- Building healthy public policy to reduce obesity.

- Create supportive environments which will mitigate obesity.

- Strengthening community action against obesity.

- Developing personal skills to control obesity.

- Re-orientating health services towards prevention of obesity and promotion of health.

The charter recognizes that health is a resource for social and developmental purposes, therefore the factors that affect these changes must be nurtured to reduce adolescent obesity. Secondly, that health equity must be attainable whereby individuals can become empowered to control their determinants of health and maintain their weight levels, to ensure the highest quality and maximization of life. Lastly, a recognition that health promotion in terms of adolescent obesity cannot be achieved by the health sector alone and that its ultimate success will depend on the collaboration from all sectors of government and interdependent organizations with a vested interest or responsibility spanning social, economic, media and industrial institutions and entities.

(WHO,2012) 


\section{Adolescent Obesity Health Prevention and Promotion Strategy}

There are a number of key strategies which must be implemented for the health promotion policy as per our five point plan. A costing and benefits analysis will also accompany each strategy to determine the usefulness and feasibility of each approach.

1. Implementation of active transportation programs - Which would encourage adolescents and their parents to walk to school instead of being driven or taking public transport. This can be overseen by a minimum of two parents who may supervise a consortium of adolescents. There are many potential benefits such as reducing traffic pollution and congestion on the roads, facilitates social networking, enhances pedestrian skills, encourages good exercise habits, and has a positive impact on family travel attitudes. The program would require a high level of ongoing funding and support to keep it operational so therefore a mass uptake is required to allow for feasibility.

\begin{tabular}{|c|c|}
\hline $2 . \quad$ Gross cost per DALY saved & $\$ 0.77 \mathrm{M}(\$ 0.24 \mathrm{M} ; \$ 3.2 \mathrm{M})$ \\
\hline $\begin{array}{c}\text { Net cost per DALY saved (with cost-offsets) with attribution } \\
\text { of costs to obesity prevention only }\end{array}$ & $\$ 0.76 \mathrm{M}(\$ 0.23 \mathrm{M} ; \$ 3.32 \mathrm{M})$ \\
\hline Overall result: & $\begin{array}{c}\text { Not cost-effective under current } \\
\text { assumptions }\end{array}$ \\
\hline
\end{tabular}

(Health Victoria, 2006)

2. Integration of family based GP mediated intervention programs : Doctors would regularly have consultations and appointments with patients whereby they would weigh them and check their BMI and ensure that they are maintain a healthy weight range. GPs can offer a range of targeted prescriptions that aim to modify behavioural determinants of the adolescent's general health, physical activity and nutrition. There are issues around equity and access to GP services which must be considered and also the stigmatisation and labelling of adolescents as 'overweight' because of the sensitivity and self-esteem issues which may lead to such behaviours including bullying and eating disorders later in life. This measure would require a sufficient capacity of trained doctors, nutritionists and dieticians to work in tandem. The many benefits include a potential positive impact on weight and general health, expanded GP training, early identification and management of obesity. 


\begin{tabular}{|c|c|}
\hline $\begin{array}{c}\text { Cost-effectiveness results (with 95\% uncertainty } \\
\text { interval) Gross cost per DALY saved }\end{array}$ & $\$ 32,000(15,000$, infinity) \\
\hline Net cost per DALY saved (with cost-offsets) & $\$ 24,000(6,000$, infinity) \\
\hline Overall result: & Cost-effective \\
\hline
\end{tabular}

(Health Victoria, 2006)

3. Laparoscopic Gastric Banding: Which would only be used in cases of extreme obesity(BMI > 35) which could contribute to premature morbidity if action is not taken to reduce the patient's weight. This is a current surgical measure used to treat and manage cases of severe or morbid obesity in adolescents. There are moderate equity concerns because it is not currently offered under the public health system. This is an expensive intervention strategy with high short term costs and low short term benefits, but the high cost is offset with the long term gains and health outcomes. The surgery capacity is currently limited by the number of qualified surgeons, high cost of state intervention and public perceptions and attitudes. The major negatives of the surgery are strict diet restrictions, vomiting and reflux, pain and complications that may post-surgery. The major benefits are an improvement in patient self-esteem and psychological function and better long term health outcomes.

\begin{tabular}{|c|c|}
\hline $4 . \quad$ Gross cost per DALY saved & $\$ 10,000(\$ 9,000 ; \$ 12,000)$ \\
\hline Net cost per DALY saved (with cost-offsets) & $\$ 4,000(\$ 3,000 ; \$ 6,000)$ \\
\hline Overall result: & Cost-effective \\
\hline
\end{tabular}

(Health Victoria, 2006)

4. Bring about a reduction in adolescent participation in excessive sedentary activities : Such as watching TV, computer usage, video games, mobile phones, tablets, laptops, etc. Only $75 \%$ of boys and girls meet the requirements of at least one hour of physical activity each day and a very high proportion of young people spend more than the recommended maximum 2 hours per day engaging in small screen activity in Australia according to SWASH(2006) therefore this is another important priority area. By curtailing excessive media consumption and computer usage, adolescents would be encouraged to engage in more outdoor physical activities and social events. This would be a cooperative approach between the teachers and parents who will restrict use of technology and devices used for entertainment purposes around the home and at school. There are difficulties to enforce this policy and the resentment and resistance by the adolescents may require stronger enforcement measures and/or penalties for any violations such as confiscating the 
offending equipment or detention. It will have a positive outcome on health and physical activity for the adolescents, improvement in social relationships and potential improvements to academic performance.

\begin{tabular}{|c|c|}
\hline Gross cost per DALY saved & $\$ 3,000(\$ 1,500, \$ 7,000)$ \\
\hline Net cost per DALY saved (with cost-offsets) & $\begin{array}{c}\text { Dominant (i.e. median cost saving of } \\
\$ 44 \mathrm{M}) \text { Range: large chance of being } \\
\text { dominant }[98.9 \%]\end{array}$ \\
\hline Overall result: & Cost- effective and cost-saving \\
\hline
\end{tabular}
(Health Victoria, 2006)

5. School-based Nutritional and Physical Education Intervention Programs : This would be implemented by a series of mandatory physical activity and dietary/healthy eating programs which would be incorporated into the student curriculum. This program aims to reduce the risks of cardiovascular diseases through education, learning, physical activity and healthy eating choices. There are some challenges involved, such as trying to implement this in schools that place a high emphasis on educational goals and may dismiss these non-academic functions as a threat to pure academic pursuits. Furthermore, uptake by schools may be limited due to financial and time commitments and possibly require the hiring of additional Physical Education(PE) teachers; therefore, it requires a large ongoing investment and time commitment by schools and the department of education.

\begin{tabular}{|c|c|}
\hline $\begin{array}{l}\text { 6. Results (with } 95 \% \text { uncertainty interval) Gross } \\
\text { cost per DALY saved }\end{array}$ & $\$ 7,000(\$ 5,000, \$ 9,000)$ \\
\hline Net cost per DALY saved (with cost-offsets) & $\begin{array}{c}\text { Dominant (i.e. median cost saving of } \\
\text { 14M) Range: large chance of being } \\
\text { dominant }[95.6 \%]\end{array}$ \\
\hline Overall result: & Cost-effective and cost-saving \\
\hline
\end{tabular}
(Health Victoria, 2006)

Referring to appendix 8, conveys a multi-dimensional approach to tackling the obesity epidemic and is necessary for our health promotion strategy to be effective. It involves a combination of the physical and cultural environment, priority risk groups and different treatment strategies for certain target groups based on age and ethnicity (SSWAHS, 2008).

Please refer to Appendices 9, 10 and 11 to see a breakdown of intervention costs, savings and benefits of some of the beforementioned approaches (Health Victoria, 2006).

According to ASSO in Appendix 5, there are a number of general dietary modifications that adolescents can follow to reduce the prevalence of obesity. These include the variety of different foods, reduced energy intake, 
substituting simple for complex carbohydrates, meal habits, beverage intake and informed food shopping choices (ASSO, 2007).

\section{Conclusion}

By adopting these measures we can help the resident adolescents of the Western Sydney Area to reduce their weight to a healthy level and prevent obesity and its related health costs and disabilities that it inflicts upon individuals. This is an overwhelming positive step in the right direction for the future of health promotion. It should be noted that these are all long term goals which will take many years to fully implement, and even longer to see the results of. For this reason, the timeframe of implementation is 3-5 years initially, and the timeframe for long term results could be 10 years or more. With continued funding and remuneration from the government, it is likely that this plan take hold until fruition. The goals that have been set for the health promotion project based on the costing are, on the whole, viable and realistic to be achievable in the medium to long term.

\section{References:}

1. ASSO(2006), Australian Society for the Study of Obesity, "Obesity in Australian Adults : Causes, Prevention and Management"

2. Australian Bureau of Statistics (2009), "National Health Survey 2008-2009", Website accessed 25/9/12 at http://abs.gov.au/AUSSTATS/abs@.nsf/DetailsPage/4364.020072008\%20(Reissue)?OpenDocument

3. Bankstown City Council (2006), Bankstown City Health Plan 20062011, Website accessed 25/9/12 at : http://www.lgsa.org.au/resources/documents/Bankstown_Health_Pl an_290507.pdf

4. Cancer Council Australia (2010), "Obesity Control in Australia : Defusing a Cancer Time Bomb, Website accessed 25/9/12 at : http://www.cancer.org.au/policy/electionpriorities2010/obesitystrateg y.htm

5. Krebs F(2007), Paediatrics : Official Journal of the American Academy of Paediatrics. "Assessment of Child and Adolescent Overweight and Obesity" J120 S93

6. Health Victoria (2006), "ACE-Obesity : Assessing Cost Effectiveness of Obesity Interventions in Children and Young Adults - Summary of Results", Victorian Government of Human Services, Website accessed 25/9/12 at http://www.health.vic.gov.au/healthpromotion/downloads/ace_obesit y.pdf 
7. Meyer, A. (2007), "Sedentary Behaviour and Physical Activity : Risk Factors Associated With Modern Lifestyles", Chapel Hill

8. NSW Health (2008), "Bankstown, Overweight and Obesity by Year, Persons Aged 16 Years and Over, NSW, 2002-2007, Website accessed 25/9/12 at

http://www.health.nsw.gov.au/PublicHealth/surveys/hsa/07dgp/bt/i_b mi/i_bmi trend.asp

9. O'Dea, J. (2006), "Health Promotion and Obesity : Childhood Obesity Prevention Strategies", Website accessed 25/9/12 at : http://her.oxfordjournals.org/content/21/6/751.full

10. Preventative Health Taskforce(2012) - "Australia: the healthiest country by 2020 National Preventative Health Strategy - the roadmap for action", Website accessed 25/9/12 at : http://www.health.gov.au/internet/preventativehealth/publishing.nsf/ Content/nphs-roadmap-toc nphs-roadmap-1 nphs-roadmap1.5 nphs-roadmap-1.5.2

11. Roth, E(2011) "Teenage Obesity in Australia", Website accessed 25/9/12 at : http://www.livestrong.com/article/352934-teen-obesityin-australia/

12. SSWAHS(2008), NSW Department of Health and Ageing "Overweight and Obesity Prevention and Management Plan 20082012".

13. SSWAHS(2006), NSW Department of Health and Ageing "Healthy Weight Strategy 2006 - 2011".

14. WHO (2012) - "Bangkok Charter", WHO Health Promotion Conference, Website accessed 25/9/12 at : http://www.who.int/healthpromotion/conferences/6gchp/bangkok_ch arter/en/index.html

15. WHO(2012) - "The Ottawa Charter for Health Promotion", WHO Health Promotion Conference, Website accessed 25/9/12 at : http://www.who.int/healthpromotion/conferences/previous/ottawa/en/ index.html 


\section{Appendices}

Appendix 1 : Bankstown City Council (2006) Bankstown City Health Plan 2006-2011

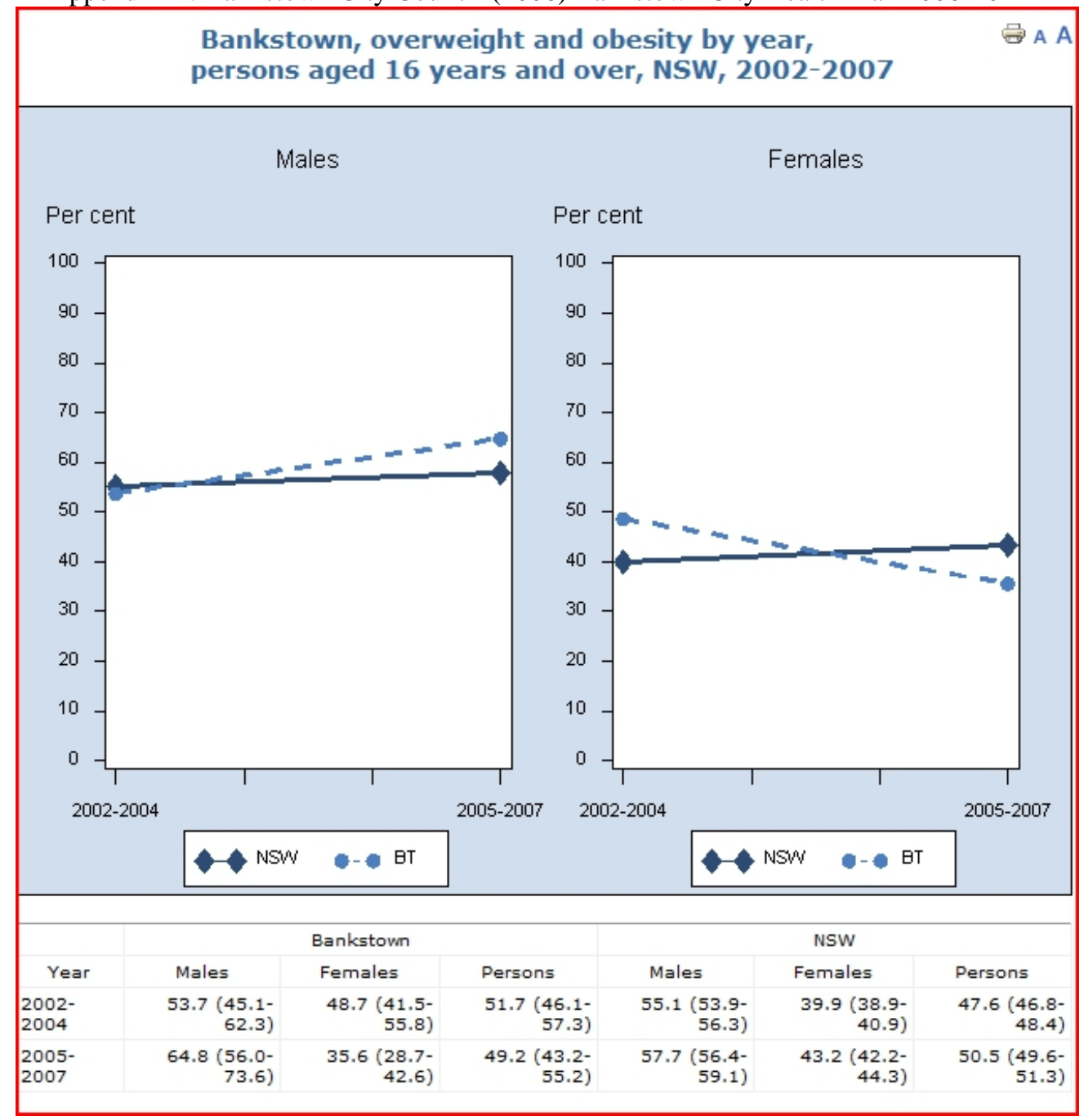




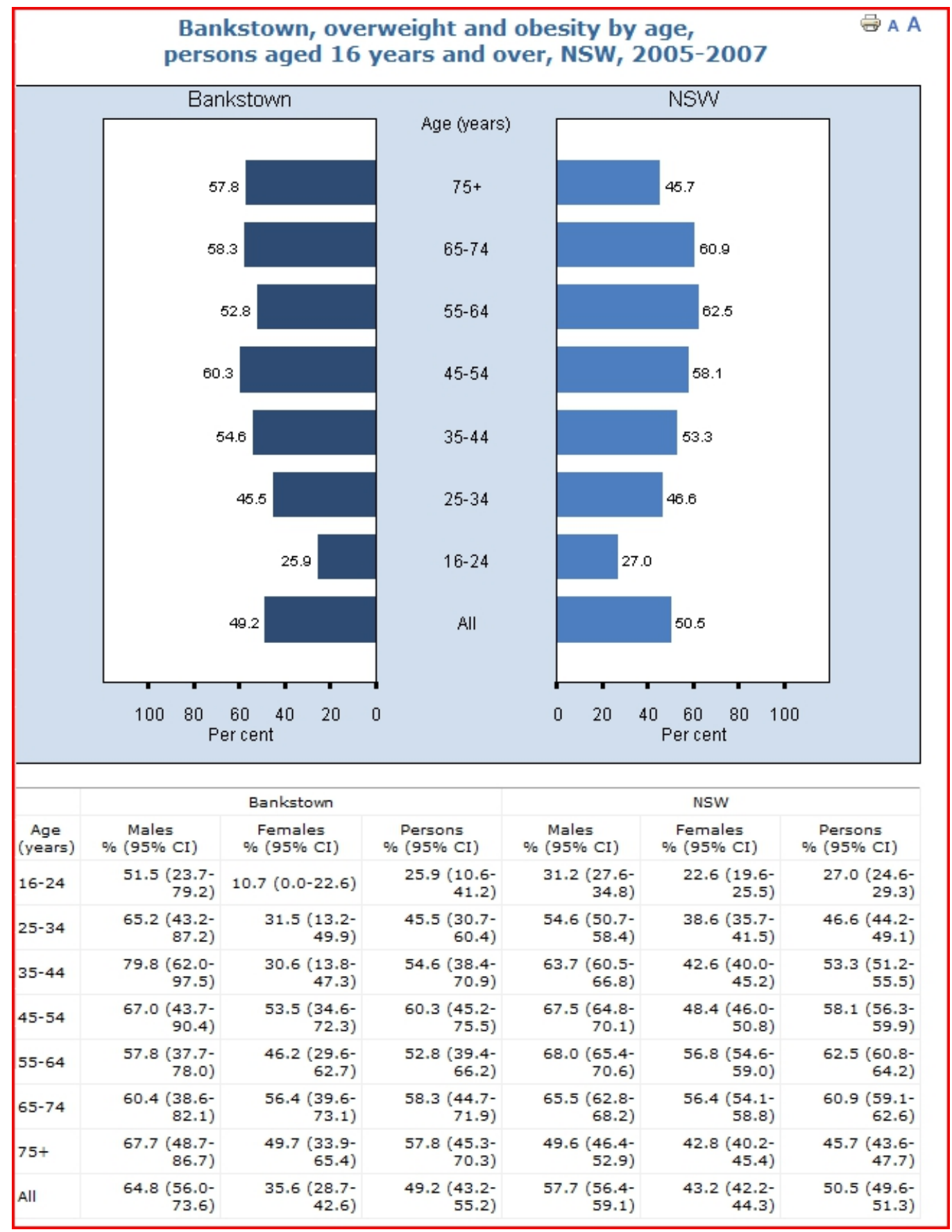

Appendix 2 : Australian Bureau of Statistics (2009) "National Health Survey 2008-2009", http://abs.gov.au/AUSSTATS/abs@.nsf/DetailsPage/4364.020072008\%20(Reissue)?OpenDocument 
Table 10.1 Percentage of Overweight and Obese People by Region in Sydney, 2002-2004

\begin{tabular}{|l|c|c|c|}
\hline Region & Male $(\boldsymbol{\%})$ & Female $(\boldsymbol{\%})$ & All $\mathbf{( \% )}$ \\
\hline Macarthur & 62.9 & 48.3 & 55.8 \\
\hline Liverpool & 60.7 & 47.5 & 53.7 \\
\hline Bankstown & $\mathbf{5 3 . 0}$ & $\mathbf{4 8 . 5}$ & $\mathbf{5 1 . 3}$ \\
\hline Western Sydney & 54.0 & 43.5 & 48.9 \\
\hline Fairfield & 51.8 & 40.1 & 46.0 \\
\hline St George & 55.6 & 32.9 & 44.6 \\
\hline Sutherland & 55.3 & 34.1 & 44.1 \\
\hline Canterbury & 48.0 & 38.3 & 42.8 \\
\hline Manly-Warringah & 52.4 & 31.9 & 42.1 \\
\hline Hornsby- Ku-ring-gai & 49.1 & 29.6 & 39.5 \\
\hline South-Eastern Sydney & 48.7 & 29.1 & 39.3 \\
\hline Central Sydney & 43.8 & 32.8 & 38.5 \\
\hline Northern Sydney & 48.8 & 20.8 & 33.6 \\
\hline Eastern Sydney & 44.1 & 21.2 & 33.0 \\
\hline NSW OVERALL & $\mathbf{5 4 . 5}$ & $\mathbf{4 0 . 0}$ & $\mathbf{4 7 . 3}$ \\
\hline
\end{tabular}

Source: NSW Health, Adult Health Surveys 2002, 2003 \& 2004

Appendix 3 : Bankstown City Council (2006) Bankstown City Health Plan 2006-2011 


\begin{tabular}{|c|c|}
\hline \multicolumn{2}{|l|}{ DIET } \\
\hline Variety & $\begin{array}{l}\text { - Include a wide variety of foods in your } \\
\text { diet in moderate amounts. }\end{array}$ \\
\hline Energy & $\begin{array}{l}\text { - Decrease the intake of foods high in } \\
\text { energy to reduce the energy density of } \\
\text { the diet. }\end{array}$ \\
\hline $\begin{array}{l}\text { Fats and } \\
\text { Protein }\end{array}$ & $\begin{array}{l}\text { - Reduce the amount of fat in your diet. } \\
\text { - Eat a diet low in saturated (or bad) fat. } \\
\text { - Choose low or reduced-fat dairy. } \\
\text { - Select lean meats and try to limit fatty } \\
\text { meats. } \\
\text { - Eat fish regularly. } \\
\text { - Limit take-away foods. } \\
\text { - Limit high fat, unhealthy snack foods. }\end{array}$ \\
\hline $\begin{array}{l}\text { Carbo- } \\
\text { hydrate }\end{array}$ & $\begin{array}{l}\text { - Increase the amount of carbohydrate in } \\
\text { your diet. } \\
\text { - Choose mainly plant-based (or } \\
\text { unrefined) foods, such as bread } \\
\text { cereals, wholegrains, rice, pasta, } \\
\text { vegetables, fruits and legumes. } \\
\text { - Increase intake of fruit and vegetables. }\end{array}$ \\
\hline Meals & $\begin{array}{l}\text { - Eat a nutritious breakfast, lunch and } \\
\text { dinner. } \\
\text { - Do not 'skip' meals. } \\
\text { - Avoid snacking regularly between } \\
\text { meals. } \\
\text { - Ensure snacks are healthy and do not } \\
\text { contribute to excess energy intake. } \\
\text { - Use healthy cooking methods. } \\
\text { - Get familiar with recommended portion } \\
\text { sizes, and consider them when eating. } \\
\text { - Decrease portion sizes, especially } \\
\text { of fast foods and takeaway foods. }\end{array}$ \\
\hline Beverages & $\begin{array}{l}\text { - Drink water rather than juice or soft } \\
\text { drinks. } \\
\text { - Restrict alcohol intake; drink alcohol in } \\
\text { moderation. }\end{array}$ \\
\hline Shopping & $\begin{array}{l}\text { - Choose foods that are low in fat, salt } \\
\text { and sugar. } \\
\text { - Read food labels when you go } \\
\text { shopping, to get familiar with products } \\
\text { and to assist food choice. }\end{array}$ \\
\hline
\end{tabular}


Appendix 5 : ASSO(2006) Australian Society for the Study of Obesity, "Obesity in Australian Adults : Causes, Prevention and Management".

\section{World Food Ene gery Consumption}

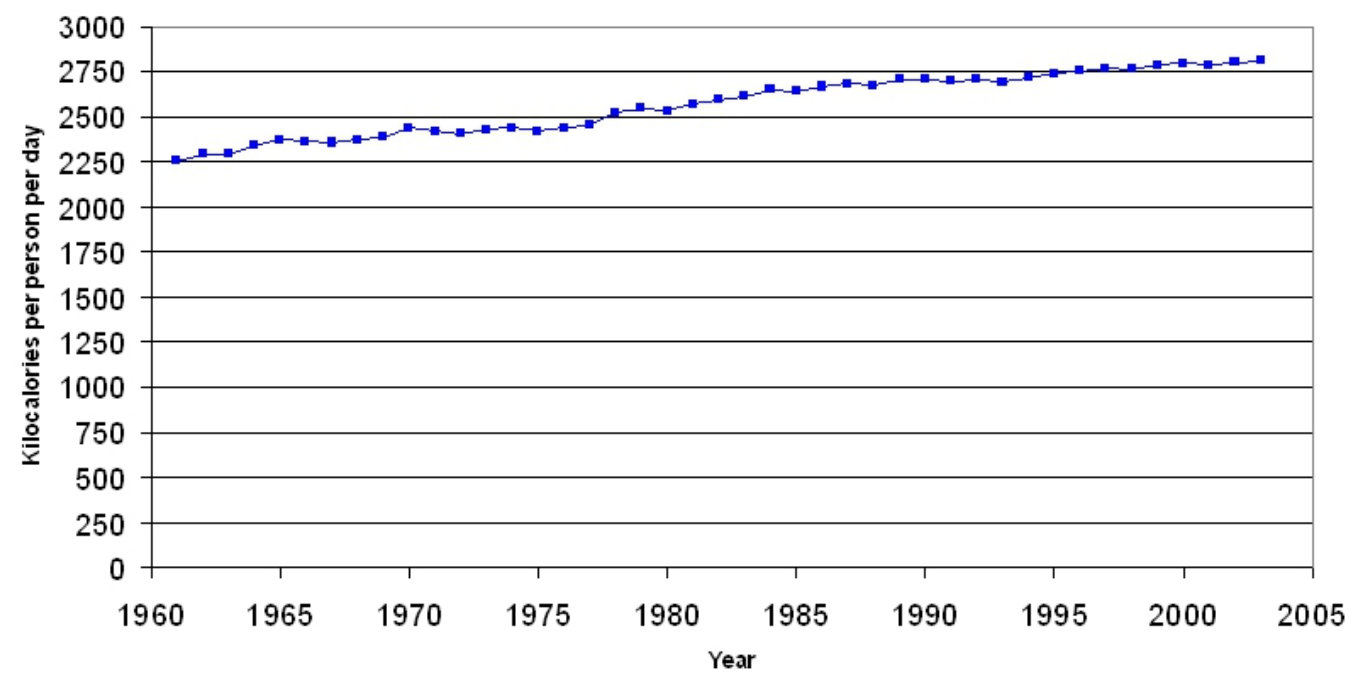

Appendix 6 : Helman, J., (2009) World Per Person Energy Consumption 1960-2005, http://en.wikipedia.org/wiki/File:World_Per_Person_Energy_Consumption.p

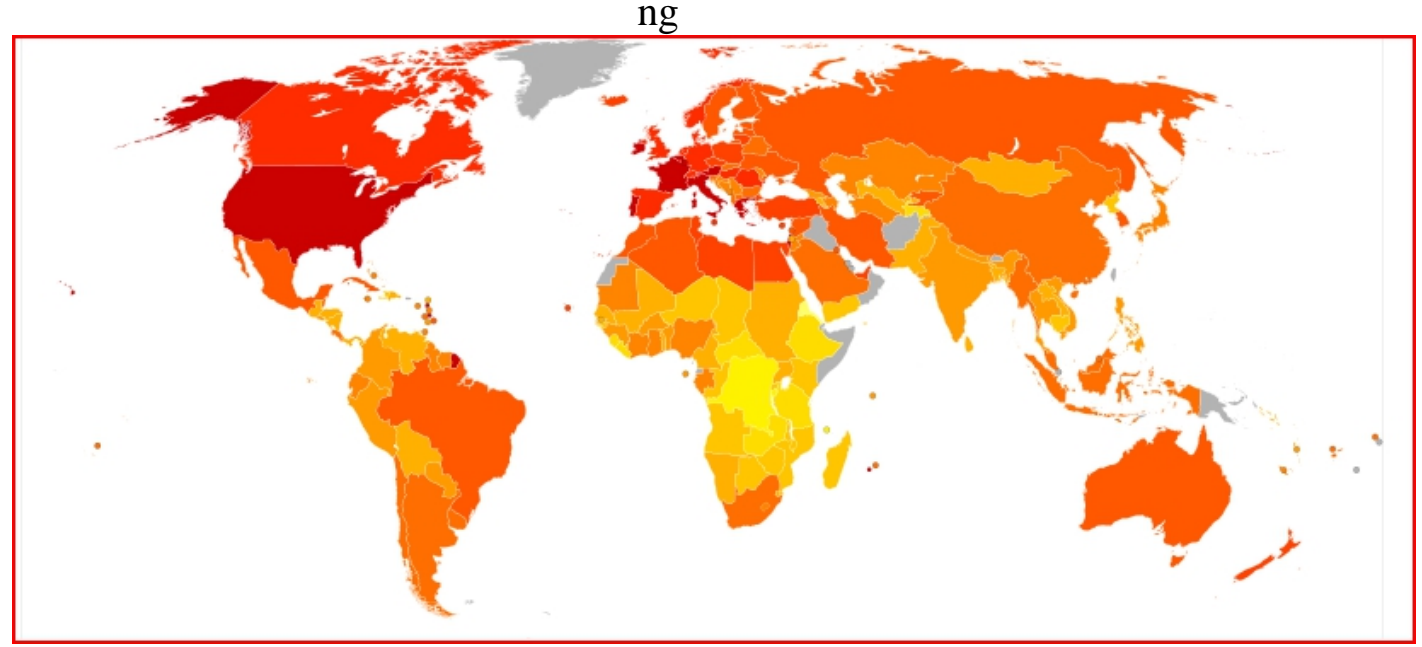

Appendix 7 : Profil, L., (2009)World Map of Energy Consumption 20012003,

http://en.wikipedia.org/wiki/File:World_map_of_Energy_consumption_2001 $\underline{-2003 . s v g}$ 


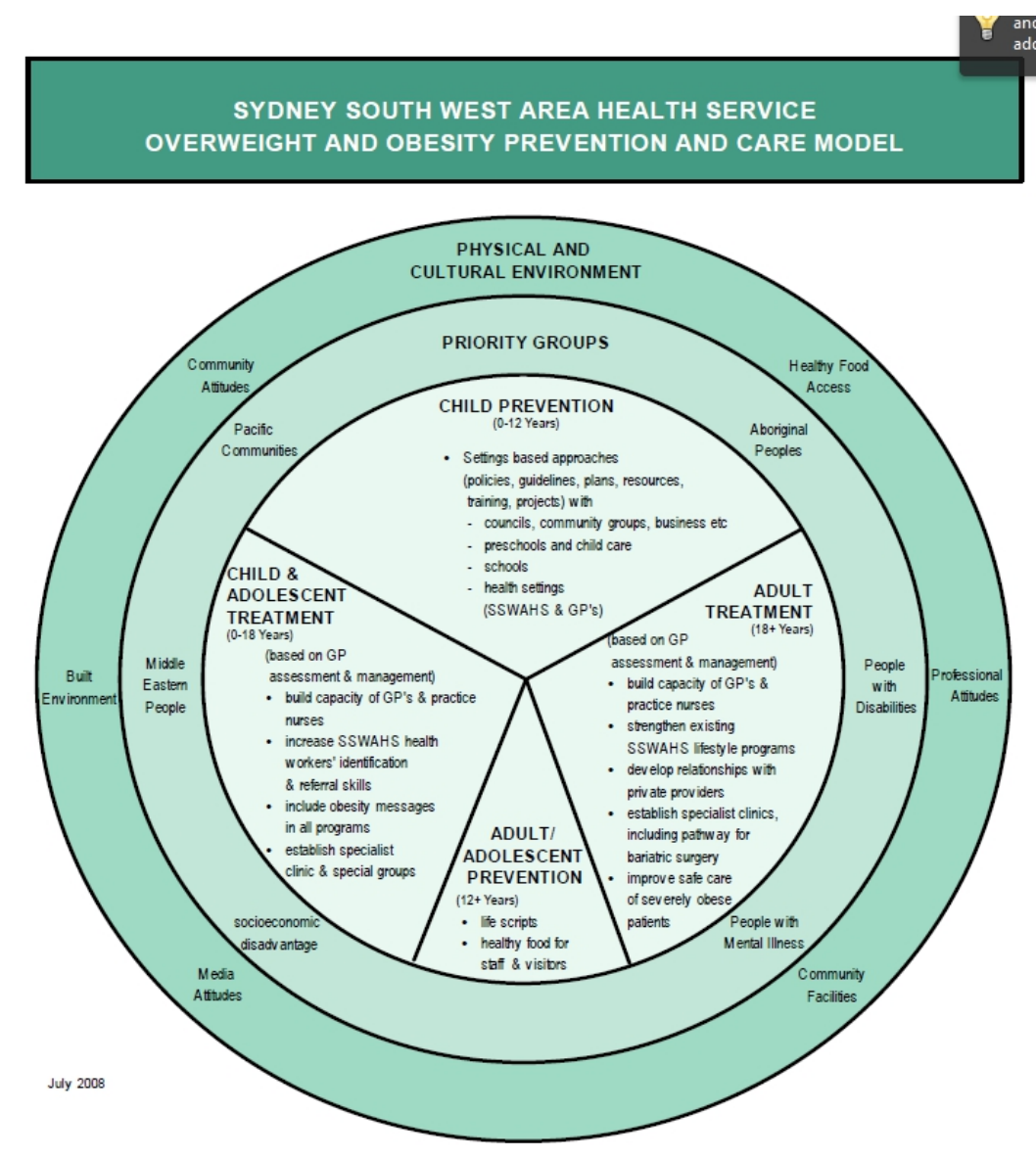

Figure 2: $\quad$ SSWAHS overweight and obesity prevention and care model

Appendix 8 : SSWAHS(2008), "Overweight and Obesity Prevention and Management Plan 2008-2012" 


\section{Incremental cost-effectiveness of interventions (net \$ per DALY saved)}

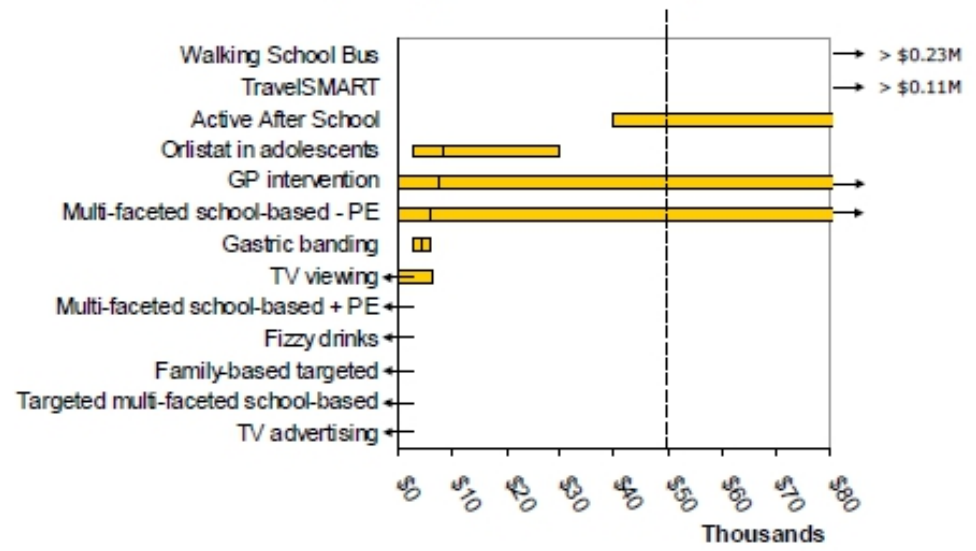

Appendix 9 : Health Victoria (2006), “ACE-Obesity : Assessing Cost Effectiveness of Obesity Interventions in Children and Young Adults -

Summary of Results", Victorian Government of Human Services, http://www.health.vic.gov.au/healthpromotion/downloads/ace_obesity.pdf

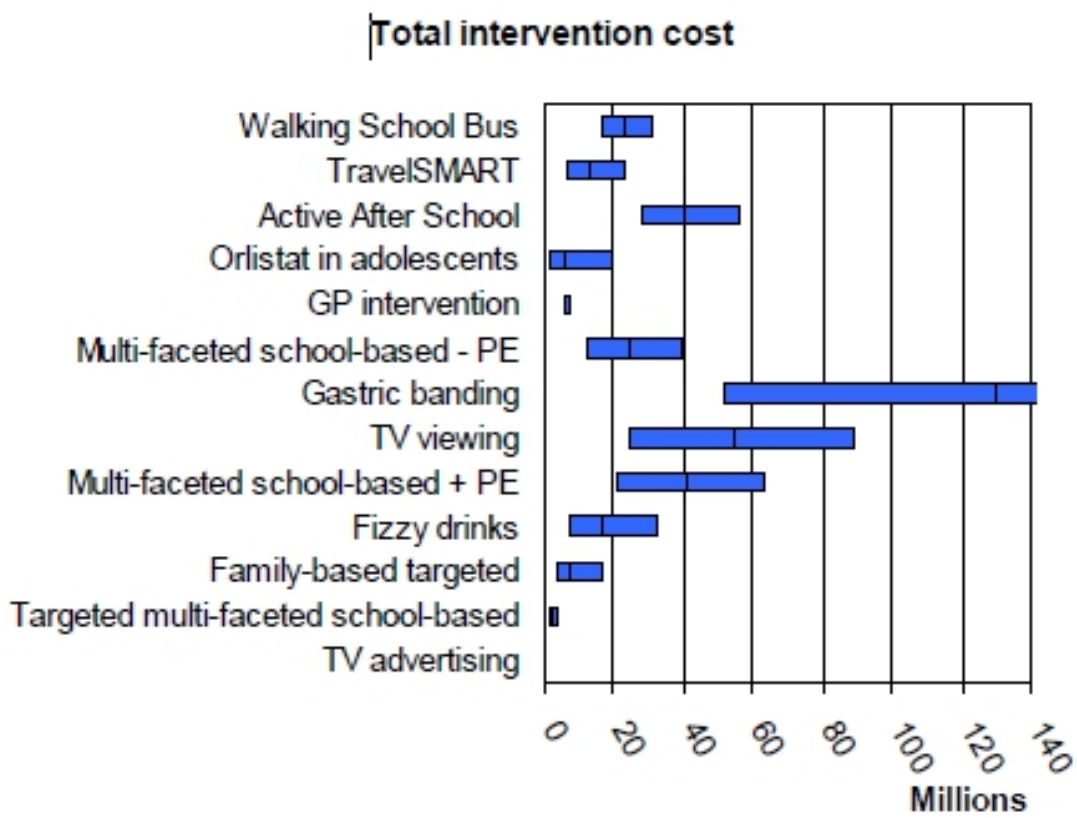

Appendix 10 : Health Victoria (2006), “ACE-Obesity : Assessing Cost Effectiveness of Obesity Interventions in Children and Young Adults - 
Summary of Results", Victorian Government of Human Services, http://www.health.vic.gov.au/healthpromotion/downloads/ace_obesity.pdf Total DALYs saved

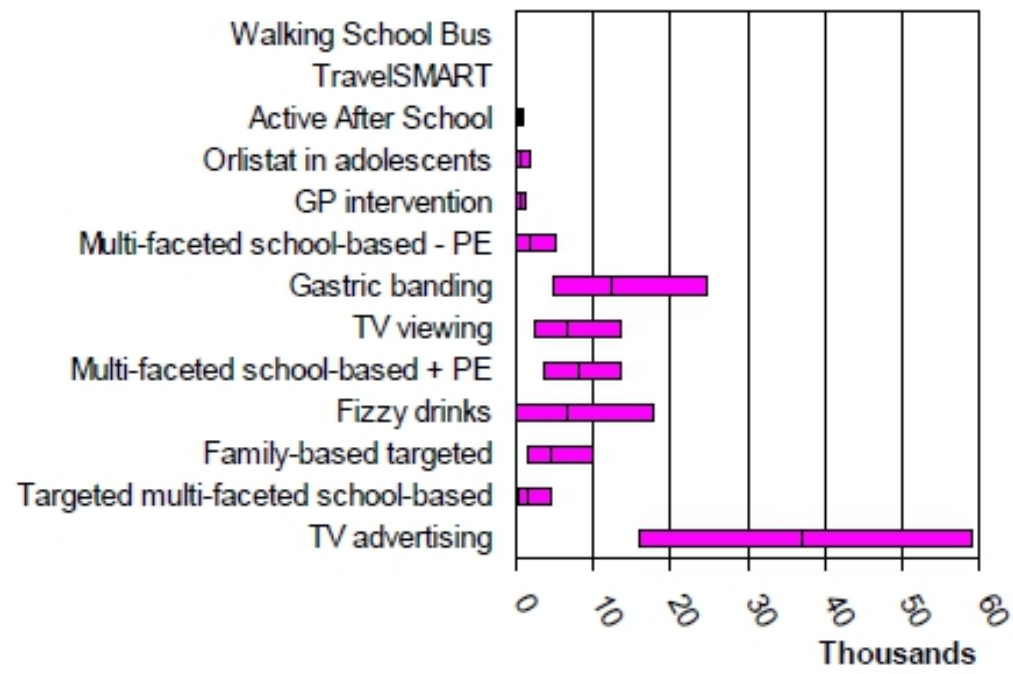

Appendix 11 : Health Victoria (2006), "ACE-Obesity : Assessing Cost Effectiveness of Obesity Interventions in Children and Young Adults -

Summary of Results", Victorian Government of Human Services, http://www.health.vic.gov.au/healthpromotion/downloads/ace_obesity.pdf

Appendix 12 :

Prevalence of overweight and obesity in Australian children aged 7-15 years, 1985-2007

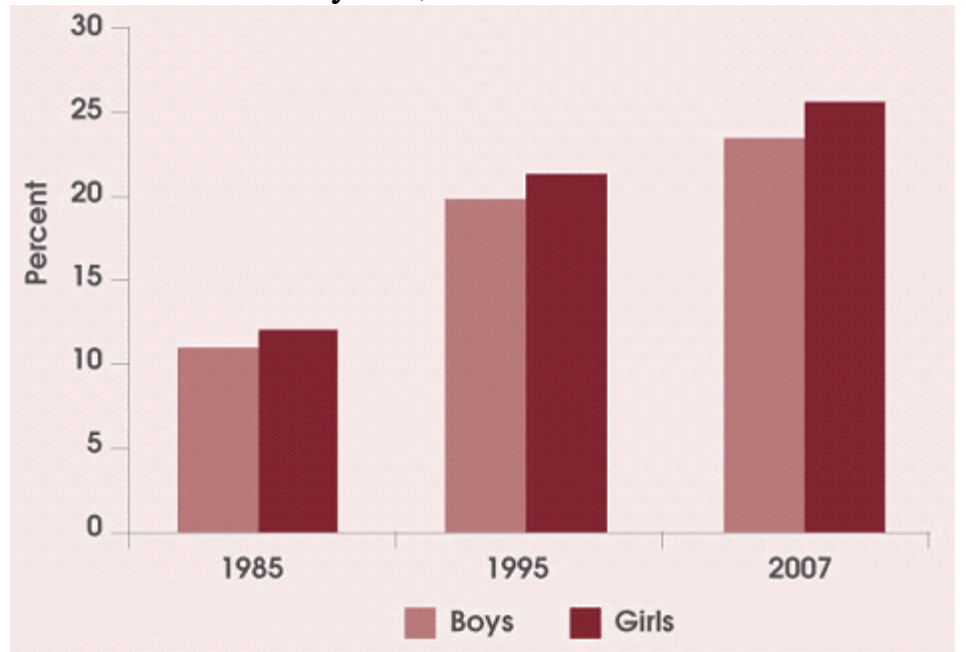

Source: Roberts L, Letcher T, Gason A, et al., (2009) 


\section{Grant Application/Proposal}

Requirement : To reduce the burgeoning levels of adolescent and teenage obesity within the Bankstown community of Western Sydney district through a combination of exercise, diet, surgery and lifestyle strategies. Timeline : 5 years to fully implement which is a medium time frame.

Goals :

Year $1:$ reduction in BMI $>25$ by $5 \%$ and medical cost savings of $3 \%$ per year $(\$ 40 \mathrm{~m})$

Year 2 : reduction in BMI $>25$ by $10 \%$ and medical cost savings of $6 \%$ per year $(\$ 80 \mathrm{~m})$

Year 3 : reduction in BMI > 25 by $15 \%$ and medical cost savings of $9 \%$ per year $(\$ 120 \mathrm{~m})$

Year 4 : reduction in BMI > 25 by $20 \%$ and medical cost savings of $12 \%$ per year $(\$ 160 \mathrm{~m})$

Year 5 : reduction in BMI > 25 by $25 \%$ and medical cost savings of $15 \%$ per year $(\$ 200 \mathrm{~m})$

Proposition : We hereby request the allocation of a suitable level of funding and financial support from the Bankstown City Council and the NSW

Department of Health to institute this five point policy which aims to reduce adolescent obesity through a range of health promotion programs. 